\title{
Emotional lability \\ in children and adolescents with Attention Deficit / Hyperactivity Disorder \\ (ADHD): \\ Clinical correlates and familial prevalence
}

Sobanski Esther, M.D..$^{1,{ }^{* *}}$ Banaschewski Tobias, M.D., Ph.D. ${ }^{2,12,{ }^{* *}}$; Chen Wai, M.R.C.P, M.R.C.Psych. ${ }^{3,4,17}$; Holtmann Martin, M.D. ${ }^{2}$; Asherson Philip, M.R.C.Psych., Ph.D. ${ }^{3}$; Stringaris Argyris, M.D., M.R.C.Psych. ${ }^{3}$; Buitelaar Jan, M.D., Ph.D. ${ }^{5}$; Franke Barbara, Ph.D. ${ }^{5,16}$; Sergeant Joseph, Ph.D. ; Sonuga-Barke, Edmund Ph.D. ${ }^{3,4,11,18, ;}$ Taylor Eric, MB, FMedSci ${ }^{3}$; Ebstein Richard P., Ph.D. ${ }^{7}$; Gill Michael, M.R.C.Psych., Ph.D. ${ }^{8}$; Miranda Ana, M.D. ${ }^{9}$; Oades Robert D., Ph.D. ${ }^{10}$; Roeyers Herbert, M.D., Ph.D. ${ }^{11}$; Rothenberger Aribert, M.D. ${ }^{12}$; Steinhausen HansChristoph, M.D., Ph.D. ${ }^{13}$; Mulas Fernando, M.D. ${ }^{9}$; Anney Richard, Ph.D. ; Krumm Bertram, Ph.D. ${ }^{15}$, Faraone Stephen V., M.D., Ph.D. ${ }^{14}$

\section{Journal of Child Psychology and Psychiatry, 51, 915-923}

\author{
This is the reformatted manuscript submitted - prior to publication in its final form at \\ (www.springerlink.com) doi:10.1111/j.1469-7610.2010.02217.x
}

** The first two authors contributed equally to this paper

Corresponding author: Email: tobias.banaschewski@zi-mannheim.de

${ }^{1}$ Department of Psychiatry and Psychotherapy, Central Institute of Mental Health, Germany

${ }^{2}$ Department of Child \& Adolescent Psychiatry, Central Institute of Mental Health, Mannheim, Germany

${ }^{3}$ MRC Social Genetic Developmental and Psychiatry Centre, Institute of Psychiatry, London, UK

${ }^{4}$ School of Psychology, University of Southampton, Highfield, Southampton, UK

${ }^{5}$ Department of Psychiatry, Donders Institute for Brain, Cognition and Behaviour, Centre for Neuroscience, Radboud University Nijmegen Medical Centre, Nijmegen, the Netherlands

${ }^{6}$ Clinical Neuropsychology, Vrije Universiteit, Amsterdam, the Netherlands

${ }^{7}$ S. Herzog Memorial Hospital, Jerusalem, Israel

${ }^{8}$ Trinity Centre for Health Sciences, St James's Hospital, Dublin, Ireland

${ }^{9}$ Department of Developmental and Educational Psychology, University of Valencia, Valencia, Spain

${ }^{10}$ University Clinic for Child and Adolescent Psychiatry and Psychotherapy, Essen, Germany

${ }^{11}$ Departments of Experimental Clinical Health Psychology, Ghent University, Belgium

${ }^{12}$ Child and Adolescent Psychiatry, University of Gottingen, Gottingen, Germany

${ }^{13}$ Department of Child and Adolescent Psychiatry, University of Zurich, Zurich, Switzerland

${ }^{14}$ Departments of Psychiatry and Neuroscience and Physiology, SUNY Upstate Medical University, Syracuse, NY, USA

${ }^{15}$ Department of Biostatistics, Central Institute of Mental Health, Germany

${ }^{16}$ Department of Human Genetics, Radboud University Nijmegen Medical Centre, Nijmegen, the Netherlands

${ }^{17}$ Clinical Neurosciences Division, School of Medicine, University of Southampton, Southampton, UK

${ }^{18}$ Child Study Centre, New York University, New York, USA.

\section{Authors' note and Acknowledgements}

The IMAGE project is a multi-site, international effort supported by NIH grant R01MH62873 to S.V. Faraone. Site Principal Investigators are Philip Asherson, Tobias Banaschewski, Jan Buitelaar, Richard P. Ebstein, Stephen V. Faraone, Michael Gill, Ana Miranda, Robert D. Oades, Herbert Roeyers, Aribert Rothenberger, Joseph Sergeant, Edmund Sonuga-Barke, and Hans-Christoph Steinhausen; Senior coinvestigators are lan Craig, Peter McGuffin, Robert Plomin, Pak Sham, Eric Taylor, Iris Manor, Jacques 
Eisenberg and Margaret Thompson. Chief Investigators are Evi Bitsakou, Marieke Altink, Wai Chen, Hanna Christiansen, Barbara Franke, Rafaela Marco, U Mueller, Fernando Mulas, Lamprini Psychogiou, Nanda Rommelse, Aisling Mulligan and Henrik Uebel. Other investigators are Catheljine Buschgens, Frits Boer, Alysa Doyle, Ellen Fliers, Alexander Heise and Ruud Minderaa. We thank all the families who kindly participated in this research.

\section{Abstract}

Background: The goal of this study was to investigate occurrence, severity and clinical correlates of emotional lability (EL) in children with ADHD, to examine factors contributing to the degree of EL and to study the familiality of EL in ADHD.

Methods: 1186 children with ADHD-combined type and 1827 siblings (aged 6-18 years) were assessed for symptoms of EL, ADHD, associated psychopathology and comorbid psychiatric disorders with a structured diagnostic interview (PACS) and parent and teacher ratings of psychopathology (SDQ; CPRS-R:L; CTRS-R:L). Analyses of variance, regression analyses, $\mathrm{X}^{2}$-tests or log-linear models were applied.

Results: Mean age and gender-standardized ratings of EL in children with ADHD were $>1.5$ SD above the mean in normative samples. Severe EL ( $>75$ percentile) was associated with more severe ADHD core symptoms, primarily hyperactive-impulsive symptoms, and highest rates of comorbid oppositional defiant, affective and substance use disorders. Age, hyperactive-impulsive, oppositional, and emotional symptoms accounted for $30 \%$ of $\mathrm{EL}$ variance; while hyperactive-impulsive symptoms did not contribute to the degree $E L$ in ADHD-combined type, if comorbid oppositional behaviour and emotional problems were taken into account, oppositional symptoms could explain $12 \%$ of EL variance specifically. Severity of EL in probands increased severity of EL in siblings but not prevalence rates of ADHD or ODD.

Conclusion: $E L$ is a frequent clinical problem in children with ADHD which is associated with increased severity of ADHD core symptoms, particularly hyperactivity-impulsivity, and a higher degree of associated psychopathological symptomatology, primarily oppositional behaviour, but also affective symptoms, and substance abuse. EL in ADHD seems to be more closely related to ODD than to ADHD core symptoms, and is only partly explainable by the severity of ADHD core symptoms and associated psychopathology. EL symptoms run within ADHD-families, but EL does not confer to the risk for ADHD or ODD in siblings.

Keywords: Attention deficit / hyperactivity disorder, emotional lability, affective lability, emotional dysregulation 


\section{Introduction}

Attention-deficit/hyperactivity disorder (ADHD) is a developmental disorder, characterized by age-inappropriate levels of inattention, impulsivity and hyperactivity, which occurs in about $5 \%$ of school-age children (American Psychiatric Association, 2000). In up to $65 \%$ of cases impairing symptoms persist into young adulthood (Faraone, Biederman \& Mick, 2006)

ADHD is often associated with symptoms of emotional lability (EL), a term which is used in this article descriptively for symptoms such as irritability, hot temper, low frustration tolerance, and sudden unpredictable shifts towards negative emotions such as anger, dysphoria and sadness, occurring in an intensity or frequency that is considered culturally inappropriate in relation to the situational context, age and developmental stage (Whalen \& Henker, 1985; Maegden \& Carlson, 2000; Nigg, Goldsmith \& Sachek, 2004; Mick, Spencer, Wozniak \& Biederman, 2005; Brotman et al., 2006; Leibenluft, Cohen, Gorrindo, Brook \& Pine, 2006; Asherson, Chen, Craddock \& Taylor, 2007). Likewise, the construct "severe mood dysregulation" (SMD) refers to children with persistent irritability, hyperarousal, and emotional overreactivity (Leibenluft et al., 2003; Brotman et al., 2006). Other mood- and emotion-related terms such as emotional dysregulation, affective lability and mood instability have often been used interchangeably in the literature. We refer to the term EL instead because it does not posit any particular deficits or underlying causes; in contrast, theoretical definitions of emotional self-regulation, respectively dysregulation, often include a more active modification or alteration of ongoing emotional responses through engagement of cognitive higher-order regulatory processes in the service of goal-directed behaviour (Gross \& Thompson, 2007; Eisenberg \& Spinrad, 2007; Zelazo \& Cunningham, 2007; Stringaris \& Goodman, 2008).

EL has been consistently noted in the changing definitions of the ADHD construct and diagnosis and is currently considered as associated feature of the disorder (Skirrow, McLoughlin, Kuntsi \& Asherson, 2009). It predicts a poorer social outcome and peer rejection in individuals with ADHD (Maedgen \& Carlson, 2000; Melnick \& Hinshaw, 2000), and treatment of ADHD symptomatology often results in improvement of EL (for a review see: Skirrow et al, 2009).

The specific relation how EL and ADHD are interconnected is still unclear and has been conceptualised in different ways. According to a prominent theoretical model of ADHD proposed by Barkley (1997), impairments in executive functions and EL could be explained by a core inhibition deficit; insufficient emotional regulation is considered to represent one consequence of deficient executive inhibitory control. However, while there is evidence that ADHD is associated with reduced emotional regulation skills and altered emotional reactivity including high levels of negative emotions (Braaten \& Rosen 2000; Maegden \& Carlson, 2000; Melnick \& Hinshaw, 2000; Walcott \& Landau, 2004), available data show only a moderate correlation between inhibitory impulse control and emotional regulation (Melnick \& Hinshaw, 2000; Walcott \& Landau, 2004). As both motivational and executive processes are likely involved in emotional responding, it still has to be clarified which particular executive function or which process is preferentially impaired in ADHD-related EL.

Furthermore, EL symptoms lack specificity for ADHD and may also occur in 
many other psychiatric disorders including anxiety, depression, bipolar disorder, oppositional defiant disorder, personality disorders, dementia (Hinshaw, 2003; Mick et al. 2005; Baroni, Lundsford, Luckenbaugh, Towbin \& Leibenluft, 2009); they are also associated with temperamental factors, such as negative emotionality (Frick \& Morris, 2004; Nigg, 2006), respectively the personality trait of neuroticism (Dyce, 1997), and may occur during normal emotional development (Gershon et al., 1996). Thus, it is unclear to what extent EL is associated with ADHD per se or whether these symptoms represent correlates of comorbid disorders.

The goal of this study was to investigate phenomenology and clinical correlates of EL symptoms in ADHD, their association with ADHD core symptoms, comorbid psychiatric disorders and demographic variables, and factors predicting $\mathrm{EL}$ severity in ADHD. Furthermore, we examined whether EL symptoms are transmitted within families, respectively whether ADHD and EL co-segregate in families. The sample of this study consists of children and adolescents with DSM-IV combined type ADHD and their siblings ascertained as part of the International Multi-centre ADHD Genetics (IMAGE) project (see: Brookes et al., 2006).

\section{Methods}

\section{Participants}

The sample consists of European Caucasian subjects recruited from twelve specialty clinics in United Kingdom, Belgium, Germany, Holland, Ireland, Israel, Spain and Switzerland. Ethical approval for the study was obtained from National Institute of Health registered ethical review boards for each centre. After a complete description of the study, informed written consent was obtained from parents and children, respectively. All ADHD probands and their siblings were between 5 to 17 years of age. At least one biological parent had to be available for DNA collection. Probands had to fulfil a diagnosis of DSM-IV ADHD combined subtype and had to have one or more full siblings available for ascertainment of clinical information and DNA collection. Probands were not included in the study if the last medication free period was more than 2 years ago. Other exclusion criteria applying to both probands and siblings included autism, epilepsy, IQ $<70$, brain disorders and any genetic or medical disorder associated with externalizing behaviours that might mimic ADHD.

\section{Procedure and diagnostic assessment}

Wherever possible, stimulant medication was withdrawn for one week prior to research assessments. Alternatively, ratings were based on medication free periods for probands that were on medication at the time of assessment.

Diagnosis of ADHD and comorbid disorders according to DSM-IV-criteria in probands was based on Parental Account of Childhood Symptoms (PACS), which is a semi-structured, standardized, investigator based interview, assessing ADHD and the most common child psychiatric disorders according to DSM-IV with good inter-rater reliability, predictive and discriminative validity. It has previously been used in a number of epidemiological, genetic and interventional studies (Taylor, Sandberg, Thorley \& Giles, 1991; Leung et al., 1996; Chen \& Taylor, 2006; Chen et al., 2008). ADHD symptoms and associated psychopathology were rated with the Strengths and Difficulties Questionnaire (SDQ; Goodman, 1997) and the Long Version of Conners' Parent and Teacher Rating Scale Revised (CPRSR:L, CTRS-R:L; Conners, Sitarenios, Parker \& Epstein, 1998; Conners, 2003). CPRS-R:L / CTRS-R:L provide transformation of raw scores into age- and gender standardized 
t-scores, which were used for data analyses.

A composite EL measure was derived from the parent and teacher rated ageand gender-standardized Conners' Global Index: Emotional Lability. We used Conners' Global Index: Emotional Lability Scale because for three reasons. First, it comprises items on (a) unpredictable mood changes, (b) temper tantrums and (c) tearfulness, and (d) low frustration tolerance (teacher version). Thus, the Teacher EL Index includes the items 'temper outbursts: explosive, unpredictable behaviour', 'crying often and easily', 'mood changes quickly and drastically', and 'demands must be met immediately easily frustrated'. The Parent EL Index comprises the first 3 items. Second, the Conners' Global Index: Emotional Lability has been validated in large community samples (Conners, 2003). Third, it has been used in several previous studies to assess EL in ADHD (Rucklidge \& Tannock, 2001; Tillman \& Geller, 2005; Grizenko, Shayan, Polotskaia, Ter-Stepanian \& Joober, 2008; Ek, Westerlund, Holmberg \& Fernell, 2008) and its discriminative power against other ADHD-symptoms has been shown by factor analysis (Westlund, Ek, Holmerg, Näswall \& Fernell, 2009).

Global learning difficulties were assessed with full IQ-scores derived from the subtests picture completion, block design, similarities and vocabulary of the Wechsler Intelligence Scale for Children (Sattler, 1992).

As PACS information was not available for all siblings, ADHD and oppositional defiant disorder (ODD) were defined based on the presence of DSM-IV defined symptoms as assessed by the CPRS-R:L. ADHD combined type was recorded as present in siblings if they had t-scores > 65 (1.5 standard deviations above the mean) in the DSM-IV ADHD total score and if also 6 out of 9 DSM-IV ADHD inattentive items and 6 out of 9 items DSM-IV ADHD hyperactive-impulsive items were rated as $2=$ moderate or $3=$ severe. Siblings with t-scores $>65$ in the DSM-IV ADHD hyperactive-impulsive score and 6 out of 9 DSM-IV ADHD hyperactive-impulsive items rated as 2 or 3 (and not fulfilling criteria for ADHD inattentive type) received a diagnosis of ADHD hyperactive-impulsive type, while siblings with t-scores $>65$ in the DSM-IV ADHD inattentive score and 6 out of 9 corresponding items rated as 2 or 3 only were recorded as ADHD inattentive type. A diagnosis of ODD was recorded as present for t-scores $>65$ in the oppositional behaviour scale and 4 or more items rated as 2 or 3: For a detailed description see: Brookes et al. (2006).

\section{Statistics}

Statistical analyses were carried out using SAS 9.1. Data analysis was based on subjects with complete data on SDQ and Conners' variables; $95 \%$ of probands and $86 \%$ of siblings were available for analyses.

As parent and teacher ratings of $\mathrm{EL}$ were only modestly correlated $(r=0.23$, $\mathrm{p}<0.0001)$ we conducted a principal component analysis (PCA) of the age- and gender- standardized CPSR: R-L and CTRS: R-L Global Index: EL t-scores in order to extract one latent dimension underlying both sets of ratings. The extracted component explained $61.6 \%$ of variance of both ratings. For EL-subgroup comparisons we then divided the ADHD-sample into a group with 'low EL' $\left(<25^{\text {th }}\right.$ percentile), 'mild to moderate $\mathrm{EL}^{\prime}\left(\geq 25^{\text {th }} \leq 75^{\text {th }}\right.$ percentile) and 'severe $\mathrm{EL}^{\prime}\left(>75^{\text {th }}\right.$ percentile) based on the derived factor scores. Group comparisons were calculated using one or two-way analyses of variance (ANOVA) with post-hoc Scheffe-tests, $X^{2}$-tests or log-linear models, whichever was most appropriate. CPRS-R: L EL t-scores were linearly 
Table 1: ADHD and related psychopathological symptoms (CPRS:R-L, CTRS:R-L; t-scores, SDQP, SDQ-T; raw scores) in ADHD with low (1), mild/moderate (2) and severe (3) EL. ANOVA with post hoc Scheffe-test. ***p $<0.001 ; * * \mathrm{p}<0.01 ;{ }^{*} \mathrm{p}<0.05$

\begin{tabular}{|c|c|c|c|c|c|c|}
\hline & $\begin{array}{c}\text { Low } \\
\text { EL (1) } n=296\end{array}$ & $\begin{array}{l}\text { Mild/moderate } \\
\text { EL (2) n=594 }\end{array}$ & $\begin{array}{c}\text { Severe } \\
\text { EL (3) } n=296\end{array}$ & df & $\mathbf{F}$ & Contrasts \\
\hline \multicolumn{7}{|c|}{ ADHD Symptoms } \\
\hline \multicolumn{7}{|l|}{ Inattention } \\
\hline CPRS & $69.1 \pm 8.7$ & $70.9 \pm 8.9$ & $72.7 \pm 8.9$ & 21185 & $12.15^{\star * \star}$ & $1<2^{*} ; 1<3^{*} ; 2<3^{*}$ \\
\hline CTRS & $60.0 \pm 9.9$ & $62.6 \pm 9.7$ & $66.3 \pm 11.8$ & 21170 & $28.51^{* \star *}$ & $1<2^{*} ; 1<3^{*} ; 2<3^{*}$ \\
\hline \multicolumn{7}{|l|}{ Hyperact./Impuls. } \\
\hline CPRS & $76.8 \pm 10.9$ & $80.8 \pm 9.9$ & $84.4 \pm 8.0$ & 21183 & $46.10^{* * *}$ & $1<2^{*} ; 1<3^{*} ; 2<3^{*}$ \\
\hline CTRS & $66.7 \pm 11.8$ & $70.2 \pm 11.3$ & $77.2 \pm 10.2$ & 21176 & $65.53^{\star * *}$ & $1<2^{*} ; 1<3^{*} ; 2<3^{*}$ \\
\hline \multicolumn{7}{|l|}{ Total DSM-IV Symp. } \\
\hline CPRS & $74.4 \pm 9.0$ & $77.6 \pm 8.84$ & $81,5 \pm 8.1$ & 21182 & $83.80^{* * *}$ & $1<2^{*} ; 1<3^{*} ; 2<3^{*}$ \\
\hline $\begin{array}{l}\text { CTRS } \\
\text { SDQ-T }\end{array}$ & $\begin{array}{c}66.0 \pm 10.3 \\
8.4 \pm 1.7\end{array}$ & $\begin{array}{c}69.3 \pm 10.0 \\
8.5 \pm 1.7\end{array}$ & $\begin{array}{c}76.3 \pm 9.6 \\
8.4 \pm 1.7\end{array}$ & $\begin{array}{ll}2 & 1181 \\
2 & 1175\end{array}$ & $\begin{array}{l}48.10^{* * *} \\
0.77\end{array}$ & $\begin{array}{c}1<2^{*} ; 1<3^{*} ; 2<3^{*} \\
\mathrm{~ns}\end{array}$ \\
\hline SDQ-P & $7.4 \pm 2.5$ & $7.8 \pm 2.1$ & $8.1 \pm 1.9$ & 21181 & $8.27^{\star * *}$ & $1<2^{*} ; 1<3^{*}$ \\
\hline \multicolumn{7}{|c|}{ Associated Psychopathology } \\
\hline \multicolumn{7}{|l|}{ Oppos./Cond. Prob. } \\
\hline CPRS & $60.4 \pm 11.1$ & $71.3 \pm 11.3$ & $79.2 \pm 8.7$ & 21184 & $197.97^{* * *}$ & $1<2^{*} ; 1<3^{*} ; 2<3^{*}$ \\
\hline CTRS & $56.0 \pm 9.8$ & $65.9 \pm 13.1$ & $77.1 \pm 12.5$ & 21180 & $148.54^{\star * *}$ & $1<2^{*} ; 1<3^{*} ; 2<3^{*}$ \\
\hline SDQ-P & $3.2 \pm 2.2$ & $4.9 \pm 2.2$ & $5.8 \pm 2.2$ & 21175 & $107.20^{\star * *}$ & $1<2^{*} ; 1<3^{*} ; 2<3^{*}$ \\
\hline SDQ-T & $1.6 \pm 1.7$ & $3.1 \pm 2.2$ & $4.6 \pm 2.4$ & 21177 & $143.51^{* * *}$ & $1<2^{*} ; 1<3^{*} ; 2<3^{*}$ \\
\hline \multicolumn{7}{|l|}{ Social/Peer Prob. } \\
\hline CPRS & $60.2 \pm 14.1$ & $68.4 \pm 14.5$ & $72.8 \pm 14.7$ & 21183 & $47.81^{* * *}$ & $1<2^{*} ; 1<3^{*} ; 2<3^{*}$ \\
\hline CTRS & $56.1 \pm 12.7$ & $60.0 \pm 12.9$ & $66.4 \pm 14.1$ & 21174 & $173.60^{* * *}$ & $1<2^{*} ; 1<3^{*} ; 2<3^{*}$ \\
\hline SDQ-P & $3,2 \pm 2.5$ & $4.0 \pm 2.6$ & $4,8 \pm 2.6$ & 21176 & $28.61^{* * *}$ & $1<2^{*} ; 1<3^{*} ; 2<3^{*}$ \\
\hline SDQ-T & $2.4 \pm 2.2$ & $3.1 \pm 2.4$ & $4.0 \pm 2.7$ & 21177 & $143.51^{* * *}$ & $1<2^{*} ; 1<3^{*} ; 2<3^{*}$ \\
\hline \multicolumn{7}{|l|}{ Anxious-Shy } \\
\hline \multicolumn{7}{|l|}{ Emotional Prob. } \\
\hline CPRS & $54.1 \pm 11.7$ & $59.6 \pm 13.7$ & $65.0 \pm 14.6$ & 21184 & $48.67^{\star * \star}$ & $1<2^{*} ; 1<3^{*} ; 2<3^{*}$ \\
\hline CTRS & $57.4 \pm 10.0$ & $64.3 \pm 11.8$ & $73.0 \pm 12.3$ & 21182 & $134.47^{* * *}$ & $1<2^{*} ; 1<3^{*} ; 2<3^{*}$ \\
\hline SDQ-P & $2.8 \pm 2.1$ & $3.8 \pm 2.4$ & $4.9 \pm 2.6$ & 21175 & $53.19^{* * *}$ & $1<2^{*} ; 1<3^{*} ; 2<3^{*}$ \\
\hline SDQ-T & $1.8 \pm 1.8$ & $2.9 \pm 2.3$ & $4.1 \pm 2.6$ & 21178 & $69.76^{\star * *}$ & $1<2^{*} ; 1<3^{*} ; 2<3^{*}$ \\
\hline $\begin{array}{l}\text { Psychosom. Symp. } \\
\text { CPRS }\end{array}$ & $54.6 \pm 12.4$ & $59.9 \pm 15.5$ & $65.4 \pm 15.8$ & 21182 & $38.34^{* * *}$ & $1<2^{*} ; 1<3^{*} ; 2<3^{*}$ \\
\hline \multicolumn{7}{|l|}{ Perfectionism } \\
\hline CPRS & $52.2 \pm 10.9$ & $56.1 \pm 11.9$ & $60.4 \pm 12.4$ & 21178 & $35.62^{\star \star \star}$ & $1<2^{*} ; 1<3^{*} ; 2<3^{*}$ \\
\hline CTRS & $52.7 \pm 9.3$ & $56.4 \pm 11.4$ & $60.9 \pm 12.4$ & 21163 & $39.10^{* * *}$ & $1<2^{*} ; 1<3^{*} ; 2<3^{*}$ \\
\hline \multicolumn{7}{|l|}{ Prosocial Behav. } \\
\hline SDQ-P & $7.1 \pm 2.3$ & $6.7 \pm 2.2$ & $6.5 \pm 2.4$ & 21175 & $6.45^{\star \star \star}$ & $1<2^{*} ; 1<3^{*}$ \\
\hline SDQ-T & $6.3 \pm 2.6$ & $5.6 \pm 2.6$ & $5.0 \pm 2.7$ & 21170 & $18.15^{\star * *}$ & $1<2^{*} ; 1<3^{*} ; 2<3^{*}$ \\
\hline
\end{tabular}


regressed on demographic and psychopathological predictors, which were selected according to available research evidence indicating an association between EL and ADHD (Maegden \& Carlson, 2000; Mick et al., 2005; Barkley, 1997; Melnick \& Hinshaw, 2000; Nigg, 2003). We then checked for independence of the identified predictors (significant inter-correlation $<0.5$ ) and included from predictors inter-correlated $\geq 0.5$ [CPRS oppositional score and SDQ conduct score $(r=0.64)$, CPRS anxious-shy score and SDQ emotional problems score $(r=0.57)$ and CPRS social problems score and SDQ peer problems score $(r=0.67)]$ the one which explained more EL variance in the single regression analyses into the hierarchical multiple regression analysis which was run 1) entering possible predictor variables in descending order of explained variance and 2) entering these predictors in ascending order.

Familial prevalence of $E L, A D H D$ and ODD in siblings were computed with a generalised linear model accounting for clustered data, as some families have multiple siblings, and number of siblings varying from one to five per proband (proc genmod, SAS).

\section{Results}

\section{Subjects}

The total sample comprised 1186 probands with a diagnosis of ADHD combined type and 1827 siblings. Mean age of probands was $10.8 \pm 2.8(5-18)$ years and of siblings $10.4 \pm 3.4(5-18)$ years $(t=-0.21, d f=1.292, n s)$. Mean IQ in probands was $99.8 \pm 15.8$ and in siblings $101.8 \pm 14.2\left(F_{1,1916}=7.97 ; p<0.005\right)$. The male/female ratio in siblings was about equal (919/909), but there were about 7 boys to one girl in the ADHD group (1033/153).

\section{Distribution and severity of emotional lability}

The mean parent-reported EL t-score (standardised for age and gender) was $68.2 \pm 16.6$ in probands and $54.3 \pm 12.8$ in siblings $\left(F_{1,2817}=757.77 ; p<0.001\right)$, and the teacher-reported EL t-scores were $68.4 \pm 15.1$ in probands and $55.5 \pm 13.6$ in siblings $\left(F_{1,2815}=586.66 ; p<0.001\right)$. The $25^{\text {th }}$ standardized percentile of $\mathrm{EL}$ ratings in probands were 57 (CPRS) and 54 (CTRS) compared to 43 (CPRS) and 45 (CTRS) in siblings. The $75^{\text {th }}$ percentile of EL ratings in probands were 79 (CPRS) and 81 (CTRS) corresponding to a score of about $3 \mathrm{SD}$ above that mean of normative samples compared to 61 (CPRS) and 63 (CTRS) in siblings.

Based on their percentiles on the PCA derived factor EL-scores, probands were classified into 3 subgroups: 296 probands were assigned to the low EL group $\left(<25^{\text {th }}\right.$ percentile), 594 probands to the mild/moderate EL group ( $225^{\text {th }}$ and $\leq 75^{\text {th }}$ percentile) and 296 probands to the severe EL group ( $>75^{\text {th }}$ percentile).

\section{Association of emotional lability with demographic and clinical characteristics}

Probands with severe EL were slightly more often female than probands with low or mild/moderate EL (low EL: $12.0 \%$, mild/moderate EL: $11.1 \%$, severe EL: $\left.17.2 \% ; \chi^{2}[2]=6.84, p<0.050\right)$ and slightly older (low EL: 10.2 $\pm 2.7 y .$, mild/moderate EL: $10.7 \pm 2.6 y .$, severe EL: $11.8 \pm 2.9 y ; F_{2,1186}$ =30.93, $\mathrm{p}<0.001$; low < mild $/$ moderate < severe EL, post-hoc Scheffe: $p<0.05)$. No differences were found for IQ (low EL: 100.7 \pm 16.3 , mild/moderate EL: $100.1 \pm$ 15.4, severe EL: $\left.97.2 \pm 15.8 ; F_{2,817}=1.48, n s\right)$.

ADHD core symptoms showed a significant positive association with increasing severity of EL, which was more pronounced for hyperactive-impulsive than for inattentive symptoms (see table 1). Increasing severity of EL was also associated with increased other psychopathological symptoms; all t-scores 
of associated psychopathological symptoms in the low EL-subgroup were within the normal range (t-scores $<60=1$ $\mathrm{SD})$, whereas in the severe EL-subgroup most of the co-existing psychopathological symptoms were rated about 1.5-2.5 SD higher than in normative samples (see table 1).

We accounted for the potential impact of gender on ADHD core and associated psychopathological symptoms and reanalyzed the data with a two-way ANOVA with the factors EL and gender. The impact of EL remained significant for all analyzed CPRS-variables (see table 1).

The total extent of CPRS-rated ADHD symptoms was influenced significantly by EL (total DSM-IV symptoms CPRS F2,1187 = 22.2; CTRS: F2,1185 = 28.4; p both $_{\text {< }} 0.010$ ) and gender (Total DSM-IV symptoms CPRS: F2,1187 = 102.6; CTRS: F2,1185 = 90.6; $p_{\text {both }}<0.010$ ), but there were no significant interaction effects between EL and gender on total ADHD symptoms or any subscale except for CRPS inattention ( $F 2,1188=3.2, p=0.040$ ).
For associated psychopathological symptoms, we found a significant impact of EL on oppositional symptoms (CPRS: F2,1187 = 103.22; CTRS: F2,1183 = 102.1; $\left.\mathrm{p}_{\text {both }}<0.010\right)$ but no significant main effect of gender or interaction. EL and gender did have an impact on social/peer problems ([EL] CPRS: F2,1187 = 29.5; CTRS: F2,1184 = 21.0; pboth < 0.010; [gender] CPRS: F2,1187 = 13,4; CTRS: F2,1184= 15.8; $\quad$ p both $_{\text {b .010), psychosomatic }}$ symptoms ([EL] CPRS: F2,1187 = 24.8; $\mathrm{p}<$ 0.010; [gender] CPRS: F2,1187 $=13.4 ; p<$ 0.010) and perfectionism ([EL] CPRS: F2,1187 = 12.6; CTRS: F2,1184 = 14.9; p both $<0.010$; [gender] CTRS: F2,1184 = 15.0; $p$ $<0.010$ ) but again, there were no significant interaction effects. However, significant effects of EL and gender on anxious shy symptoms were modulated by a significant interaction ([EL] CPRS: $F 2,1187=34.4 ; p<0.010$; [gender] CPRS: $F 2,1187=6.0 ; p<0.010 ;$ [interaction] $F 2,1187=5.1 ; p<0.010)$. Girls were rated as more inattentive and anxious/shy than boys, and the aggravating effects of EL on inattention and anxiety symptoms were stronger for girls than for boys.

\begin{tabular}{|l|c|c|c|c|c|}
\hline & $\begin{array}{c}\text { Low } \\
\text { EL (1) } \\
(\mathrm{n}=296)\end{array}$ & $\begin{array}{c}\text { Mild/moderate } \\
\text { EL (2) } \\
(\mathrm{n}=594)\end{array}$ & $\begin{array}{c}\text { Severe } \\
\text { EL (3) } \\
(\mathrm{n}=296)\end{array}$ & $\chi \mathbf{2}$ & Contrasts \\
\hline Oppositional defiant disorder & $136(46 \%)$ & $397(65.1 \%)$ & $234(79.1 \%)$ & $\begin{array}{c}74.14^{* *} \\
*\end{array}$ & $\begin{array}{c}1<2^{* * *}, \\
1<3^{* * *} \\
2<3^{* * *}\end{array}$ \\
\hline Conduct Disorder & $36(12.2 \%)$ & $153(25.8 \%)$ & $107(36.1 \%)$ & $\begin{array}{c}46,66^{* *} \\
*\end{array}$ & $\begin{array}{c}1<2^{* * *} \\
1<3^{* * *} \\
2<3^{* *}\end{array}$ \\
\hline Tourette's Syndrome & $3(1 \%)$ & $14(2.4 \%)$ & $8(2.7 \%)$ & $2.43 \mathrm{~ns}$ & \\
\hline Depression & $32(10.8 \%)$ & $100(16.8 \%)$ & $66(22.3 \%)$ & $\begin{array}{c}14.21^{* *} \\
*\end{array}$ & $1<2^{*}, 1<3^{* * *}$ \\
\hline Bipolar disorder & 0 & $4(0.7 \%)$ & $4(1.4 \%)$ & $4.07 \mathrm{~ns}$ & \\
\hline Anxiety disorders & $123(41.2 \%)$ & $274(46.1 \%)$ & $133(44.9 \%)$ & $1.37 \mathrm{~ns}$ & \\
\hline Obsessive-compulsive disorder & $5(2.4 \%)$ & $6(1.8 \%)$ & $6(2.7 \%)$ & $1.41 \mathrm{~ns}$ & \\
\hline Substance use disorder & $2(0.7 \%)$ & $11(2 \%)$ & $13(4.4 \%)$ & $10.26^{*}$ & $1<3^{* * *}$ \\
\hline
\end{tabular}

Table 2: Comorbid psychiatric disorders in ADHD with (1) low, (2) mild/moderate, (3) severe EL. Contrasts:

$\chi 2$-test with Bonferroni correction for 3 comparisons (corrected $\mathrm{p} \leq 0.002$ ). ${ }^{* * *} \mathrm{p}<0.001 ; * * \mathrm{p}<0.002 ; *<0.005$. 


\begin{tabular}{|c|c|c|c|}
\hline & $\mathbf{R}^{2}$ & beta & $\mathbf{F}$ \\
\hline \multicolumn{4}{|c|}{ Model 1} \\
\hline CPRS oppositional & 0.25 & 0.413 & $394.08 * * *$ \\
\hline SDQ-P emotional problems & 0.27 & 0.114 & $215.29 * * *$ \\
\hline CPRS hyperactive/impulsive & 0.27 & 0.037 & 143.96 \\
\hline CPRS social problems & 0.27 & 0.087 & 108.75 \\
\hline Age & 0.29 & 0.137 & $97.35 * * *$ \\
\hline CPRS cognitive inattention & 0.29 & -0.034 & 81.62 \\
\hline IQ & 0.30 & 0.015 & 48.29 \\
\hline \multicolumn{4}{|c|}{ Model 2} \\
\hline IQ & 0.01 & 0.015 & 5.00 \\
\hline CPRS cognitive inattention & 0.03 & -0.034 & 11.49 \\
\hline Age & 0.07 & 0.137 & $18.86^{* * *}$ \\
\hline CPRS social problems & 0.13 & 0.087 & 30.36 \\
\hline CPRS hyperactive/impulsive & 0.15 & 0.037 & $28.73^{*}$ \\
\hline SDQ-P emotional problems & 0.18 & 0.114 & $29.977 * * *$ \\
\hline CPRS oppositional behavior & 0.30 & 0.413 & $48.29 * * *$ \\
\hline
\end{tabular}

predicted by oppositional behaviour (CPRS-R: L oppositional behaviour score: $p<0.001$ ) and conduct problems (SDQ conduct score: $\mathrm{p}<0.001)$, which explained $25 \%$ and $15 \%$ of the variance, respectively. Emotional problems (SDQ emotional score: $R^{2}=0.09$, $p<0.001)$, anxious-shy behaviour (CPRS-R: $L$ anxious-shy behaviour score: $\quad R^{2}=0.08, \quad p<0.001$ ), hyperactive-impulsive symptoms (CPRS-R: L hyperactivity impulsivity score: $\left.R^{2}=0.08, p<0.001\right)$ and social problems (CPRS-R: $L$ social problem score: $R^{2}=0.07, p<0.001$ ) each explained between $7 \%$ and $9 \%$ of EL variance. IQ, age and cognitive-inattentive symptoms explained less than $1 \%$ of the variance.

Table 3: Stepwise multiple regression analyses for prediction of EL, in which the variables were included in the quoted order. $* * * \mathrm{p}<0.001, *<0.05$

\section{Association of emotional lability with comorbid psychiatric disorders}

The highest rates of ADHD with comorbid oppositional defiant and conduct disorders, affective disorders and substance use disorders were found in the severe EL subgroup. Results are listed in Table 2. We accounted for possible gender effects by re-analyzing the data with loglinear models. The impact of $E L$ on comorbidity remained significant; we found no impact of gender on comorbid disorders with the exception of depression, which was more frequent in girls $(25.2 \%)$ than in boys (17.1\%; v2[1] = $6.18 ; p=.010)$. Three-way interactions of $\mathrm{EL}$, gender and comorbid disorders were not observed.

\section{Predictive factors contributing to emotional lability in ADHD}

In simple regression analyses EL was
In the stepwise multiple regression model, all entered variables together explained $30 \%$ of the EL variance $(p<0.001)$ with oppositional behaviour having the strongest impact (beta $=0.413$, $p<0.001$ ), followed by age (beta $=0.137$, $p<0.001$ ), emotional problems (beta= $0.114, p<0.001)$ and hyperactive-impulsive symptoms (beta $=0.037, \mathrm{p}<0.050$ ). Oppositional behavior predicted $25 \%$ of the variance if introduced as first variable and $12 \%$ if introduced as last variable (see table 3 ). While the former three variables significantly explained incremental variance in both regression models, hyperactive-impulsive symptoms could not add incremental explained variance if entered after oppositional behavior score and emotional problems score.

\section{Familial prevalence of EL, ADHD and ODD}

Probands with severe EL more often had siblings with high EL (27.7\%) than probands with low EL (20\%). Likewise, probands with low EL more often had 


\begin{tabular}{|c|c|c|c|c|c|c|c|c|c|c|c|c|}
\hline $\begin{array}{l}\text { EL in } \\
\text { siblings } \\
\text { Proband- } \\
\text { sib-pairs. } \\
\text { EL in ADHD }\end{array}$ & $\begin{array}{c}\text { Low } \\
E L\end{array}$ & $\begin{array}{c}\text { Mild / } \\
\text { Moderate } \\
\text { EL }\end{array}$ & $\begin{array}{c}\text { High } \\
E L\end{array}$ & $\begin{array}{l}\text { Risk } \\
\text { (high } \\
\text { /low } \\
\text { EL) }\end{array}$ & $\begin{array}{l}\text { (4b) ADHD } \\
\text { in siblings } \\
\text { Proband- } \\
\text { sib-pairs } \\
\text { EL in ADHD }\end{array}$ & $\begin{array}{c}N o \\
A D H D \\
(n=1386)\end{array}$ & $\begin{array}{c}\text { ADHD } \\
\text { all } \\
\text { subtypes } \\
(n=193)\end{array}$ & $\begin{array}{c}\text { Risk } \\
\text { (ADHD } \\
/ \\
\text { no } \\
\text { ADHD) }\end{array}$ & $\begin{array}{l}\text { ODD in } \\
\text { siblings } \\
(n=1531)\end{array}$ & $\begin{array}{l}\text { No ODD } \\
(n=1294)\end{array}$ & $\begin{array}{c}O D D \\
(n=237)\end{array}$ & $\begin{array}{c}\text { Risk } \\
\text { (ODD } \\
\text { / } \\
\text { no } \\
\text { ODD) }\end{array}$ \\
\hline $\begin{array}{l}\text { Low EL } \\
(n=385)\end{array}$ & $\begin{array}{l}123 * \\
(32 \%)\end{array}$ & $\begin{array}{c}185 \\
(48 \%)\end{array}$ & $\begin{array}{c}77 * \\
(20 \%)\end{array}$ & 0.63 & $\begin{array}{l}\text { Low EL } \\
(n=385)\end{array}$ & $\begin{array}{c}343 \\
(89.1 \%)\end{array}$ & $\begin{array}{c}42 \\
(10.9 \%)\end{array}$ & 0.12 & $\begin{array}{l}\text { Low EL } \\
(n=376)\end{array}$ & $\begin{array}{c}328 \\
(87.2 \%)\end{array}$ & $\begin{array}{c}48 \\
(12.8 \%)\end{array}$ & 0.15 \\
\hline $\begin{array}{l}\text { Mild/moderate } \\
\text { EL } \\
(n=801)\end{array}$ & $\begin{array}{c}200 \\
(25 \%)\end{array}$ & $\begin{array}{c}408 \\
(50.9 \%)\end{array}$ & $\begin{array}{c}193 \\
(24.1 \%)\end{array}$ & 0.97 & $\begin{array}{l}\text { Mild/moderate } \\
E L(n=801)\end{array}$ & $\begin{array}{c}699 \\
(87.3 \%)\end{array}$ & $\begin{array}{c}102 \\
(12.7 \%)\end{array}$ & 0.15 & $\begin{array}{l}\text { Mild/moderate } \\
\text { EL }(n=774)\end{array}$ & $\begin{array}{c}643 \\
(83.1 \%)\end{array}$ & $\begin{array}{c}131 \\
(16.9 \%)\end{array}$ & 0.20 \\
\hline $\begin{array}{l}\text { Severe EL } \\
(n=390)\end{array}$ & $\begin{array}{c}101 * \\
(25.9 \%)\end{array}$ & $\begin{array}{c}185 \\
(47.4 \%)\end{array}$ & $\begin{array}{c}104 * \\
(27.7 \%)\end{array}$ & 1.03 & $\begin{array}{l}\text { Severe EL } \\
(n=390)\end{array}$ & $\begin{array}{c}341 \\
(87.4 \%)\end{array}$ & $\begin{array}{c}49 \\
(12.6 \%)\end{array}$ & 0.14 & $\begin{array}{l}\text { Severe EL } \\
(n=381)\end{array}$ & $\begin{array}{c}323 \\
(84.8 \%)\end{array}$ & $\begin{array}{c}58 \\
(15.2 \%)\end{array}$ & 0.18 \\
\hline $\begin{array}{l}\text { Odds ratio } \\
\text { (severe / low EL) }\end{array}$ & & & & 1.63 & $\begin{array}{l}\text { Odds Ratio } \\
\text { (severe / low EL) }\end{array}$ & & & 1.19 & $\begin{array}{l}\text { Odds Ratio } \\
\text { (severe / low EL) }\end{array}$ & & & 1.20 \\
\hline
\end{tabular}

Table 4:

a) Frequency of low, moderate and high EL (row percents), risk (high vs. low EL in siblings) and odds ratio (risk of high EL in siblings of probands with severe / low EL) in siblings of ADHD probands with low, moderate and severe EL. Generalised equation model: ${ }^{*} \mathrm{p}<0.050$.

b / c) Frequency of ADHD (b) and ODD (c) (row percents), risk (ADHD all subtypes / no ADHD; ODD / no ODD) in siblings of ADHD-probands with different EL-severity degrees and odds ratio of ADHD and ODD in siblings of probands with severe / low EL; Generalised equation model: *p $<0.050$. 
siblings with low EL (32\%) than probands with severe EL (25.9\%; $z=2.14, p<0.050)$. Siblings of ADHD probands with severe EL had an significantly elevated risk for high vs. low. EL (OR=1.63). Prevalence rates of ADHD and ODD in siblings were analyzed in 1186 probands with three EL-severity levels and between one and five siblings (see table 4). In total, 145 of 1579 siblings received a diagnosis of ADHD (any subtype) (9.5\%) and 115 (7.5\%) of siblings were diagnosed with ADHD-combined type; 237 of 1529 siblings received a diagnosis of ODD (15.5\%). No differences were found for prevalence rates of ADHD and ODD between siblings of probands with low or mild/moderate vs. severe EL $(z=1.08, n s ; z=-0.60, n s)$. Furthermore, probands with low, mild/moderate and severe EL had similar rates of siblings with ADHD plus high EL $\left(>75^{\text {th }}\right.$ percentile of EL ratings in siblings), which occurred in $4.6 \%, 7.0 \%$ and $7.7 \%$ of the siblings, respectively $(z=1.99, n s ; z=.76, n s$.$) .$

\section{Discussion}

Our study shows that a clinically significant degree of EL does occur in many, but not all, children and adolescents with ADHD combined type; the severity of EL in our low EL group did not differ from EL severity in a normative control group (Conners, Sitarenios, Parker, \& Epstein, 1998; Conners, 2003). Probands with severe EL were slightly older and more often female than those with mild or moderate EL. This suggests that among ADHD patients, EL symptoms might be more prominent in girls than in boys, and in older children compared with younger children. Alternatively, EL may be less acceptable in girls and older children.

High EL was associated with more severe ADHD core symptoms and with a higher prevalence of oppositional behavior, anxiety, affective symptoms, and substance abuse, whereas ratings of comorbid psychopathological symptoms in the low EL group were within the normal range. Results were not statistically different between boys and girls. In line with previous findings (Maedgen \& Carlson, 2000; Hinshaw, 2003; Castellanos, Sonuga-Barke, Milham, \& Tannock, 2006), EL was more strongly associated with hyperactive-impulsive symptoms than with inattentive symptoms, and was particularly associated with aggressive symptoms (Melnick \& Hinshaw, 2000). However, multiple regression results indicated that hyperactive-impulsive symptoms did not contribute to the degree of EL in ADHD combined type once comorbid oppositional behavior and emotional problems had been taken into account, while the reverse was not the case. Taken together, these results indicate that EL might be more closely linked to ODD-type psychopathology than to ADHD core symptoms.

However, it is important to note that significant EL symptoms are by no means a necessary accompaniment of ODD: $46 \%$ of probands with low EL also presented with ODD. These findings are in keeping with results suggesting that symptoms such as anger and temper tantrums may represent an irritable dimension of oppositional problems (Stringaris \& Goodman, 2009). A high level of EL (about 3 SD above the ageand gender-standardized mean), on the other hand, does not necessarily imply a diagnosis of ODD, and ODD as such only explains $12 \%$ of the $E L$ variance, indicating that EL in ADHD is not merely an epiphenomenon of comorbid ODD. This finding argues against the possibility that EL in ADHD is simply an extreme form or the most severe end of the ODD dimension.

The increased prevalence of depressive disorders in children with EL symptoms, and the finding from the multiple regression that emotional symptoms independently predict a small amount of 
EL variance, also point to a link between $E L$ and affective disorders in ADHD. This finding is in line with results from recent studies that children with ADHD and persistent irritability, hyperarousal, and emotional overreactivity labelled as 'severe mood dysregulation' may be at risk for depressive disorders (Baroni et al., 2009).

Taken together, the findings of this study show that EL in ADHD is not merely a correlate of ADHD core symptom severity and associated psychopathology: Firstly, $70 \%$ of EL variance could not be explained by severity of ADHD symptoms or associated psychopathological symptoms; secondly, EL in probands was associated with a significantly increased risk for $E L$ in their siblings, although $E L$ in probands was not associated with an increased risk for ADHD or ODD in their siblings; and, thirdly, there was no evidence of a co-segregation of EL with ADHD. These findings are in line with a recent epidemiological study in British children and adolescents (Stringaris \& Goodman, 2008), which also suggested that symptoms of emotional or mood lability are not a mere consequence of other psychopathology. The lack of cotransmission of EL and ADHD does not support the notion that ADHD plus EL might indicate a distinct subtype.

Alternatively, it might be possible that $E L$ in ADHD is associated with particular neuropsychological impairments, such as impaired executive functions, or motivational alterations, which are associated with ADHD (Willcutt, SonugaBarke, Nigg, \& Sergeant, 2008). Executive dysfunctions, reward processing, and emotional self-regulation all involve closely related neuroanatomical circuits and neurotransmitter systems (Nigg \& Casey, 2005). A preferential relationship between impaired inhibitory functions, ADHD and EL has been postulated
(Barkley, 1997), but the relative contribution of different executive functions to $E L$ has not yet been systematically investigated; if an association between particular executive dysfunctions and EL could be established, it might still be possible that both may - at least partly - reflect a more generalized deficit such as state regulation problems, or be a secondary consequence of motivational alterations, such as an increased sensitivity to delay (Skirrow et al., 2009; Sonuga-Barke, 2003). Thus, further studies that simultaneously investigate $A D H D, E L$, and their underlying structural and functional brain correlates are required to further characterize the relationship between EL and ADHD.

Several limitations must be considered when interpreting our findings. Most importantly, this was a post-hoc analysis of an existing dataset. The study was conducted in a clinical rather than an epidemiological ADHD sample, which potentially biased the results towards a higher severity of ADHD and associated symptoms. Finally, the study design is unable to clarify whether the familial association of $E L$ is the result of genetic or shared environmental factors. Future studies should therefore be conducted in epidemiological samples and using more detailed measurements of EL as well as genetically sensitive designs that incorporate appropriate control family and twin data. 


\section{Key points}

\section{Known}

A clinically significant degree of emotional lability does occur in numerous, but not all children and adolescents with ADHD combined type

\section{New}

EL is associated with increased severity of ADHD core symptoms, particularly hyperactivityimpulsivity, and a higher degree of associated psychopathological symptomatology, primarily oppositional behaviour, but also affective symptoms, and substance abuse.

EL and comorbid ODD psychopathology might be more closely related than EL and ADHD core symptoms.

EL in ADHD is only partly explainable by the severity of ADHD core symptoms and associated psychopathology.

EL symptoms run within ADHD-families, but EL does not confer to the risk for ADHD or ODD in siblings.

\section{Clinical relevance}

Children with ADHD should be carefully evaluated for the presence of EL. Since EL is associated with high levels of co-existing psychopathology and a well-known risk factor for impaired social interactions it should be addressed in the context of ADHD therapy. 


\section{References}

American Psychiatric Association (2000). Diagnostic and Statistical Manual of Mental Disorders $\left(4^{\text {th }}\right.$ Ed revised). Washington, DC: American Psychiatric Press.

Asherson P, Chen W, Craddock B \& Taylor E (2007). Adult attention-deficit / hyperactivity disorder: recognition and treatment in general adult psychiatry. British Journal of Psychiatry, 190, 4-5.

Baroni, A., Lunsford, J.R., Luckenbaugh, D.A., Towbin, K.E., Leibenluft, E. (2009). The assessment of bipolar disorder in children and adolescents. Journal of Child Psychology \& Psychiatry. 50: 203215.

Barkley RA (1997). Behavioral inhibition, sustained attention, and executive functions: constructing a unifying theory of ADHD. Psychological Bulletin, 121, 65-94.

Braaten, E.B., \& Rosen L.A. (2000). Selfregulation of affect in ADHD and nonADHD boys: differences in empathic responding. J Consult Clin Psychol 68: 313-321.

Brookes KJ and the Image Consortium. (2006). The analysis of 51 genes in DSM-IV combined type attention deficit hyperactivity disorder: association signals in DRD4, DAT1 and 16 other genes. Molecular Psychiatry, 11, 10: 934-953.

Brotman MA, Schmajuk $M$, Rich BA, Dickstein DJ, Guyer AE, Costello EJ, Egger HL, Angold A, Pine DS, Leibenluft E (2006). Prevalence, clinical correlates, and longitudinal course of severe mood dysregulation in children. Biological Psychiatry, 60, 991-997

Castellanos FX, Sonuga-Barke E, Milham MP \& Tannock R (2006) Characterizing cognition in ADHD: beyond executive dysfunction. Trends in Cognitive Science, 10, 117-123.

Chen W \& Taylor E (2006). Parental Account of Children's Symptoms (PACS), ADHD Phenotypes and its application to molecular genetic studies. In RD Oades (Ed), AttentionDeficit / Hyperactivity Disorder (ADHD) and the Hyperkinetic Syndrome (HKS): Current Ideas and Ways forward (pp. 320). Nova Science Publisher.

Chen W and the Image Consortium (2008). DSM-IV combined type ADHD shows familial association with sibling trait scores: A sampling strategy for QTL linkage. American Journal of Medical Genetics, Part B Jan 11; [Epub ahead of print]

Conners CK, Sitarenios G, Parker JDA \& Epstein JN (1998). The revised Conners' parent rating scale (CPRS-R): Factor structure, reliability, and criterion validity. Journal of Abnormal Child Psychology, 26, 257-268

Conners CK (2003). Conners' Rating Scales-Revised: Technical Manual. New York: Multi-Health System Inc.

Dyce JA (1997). The big five factor of personality and their relationship to personality disorders. Journal of Clinical Psychiatry, 53, 587-593.

Ek U, Westerlund J, Holmberg K, Fernell E (2008) Self-esteem in children with attention and/or learning deficits: the importance of gender. Acta Paediatrica 97, 1125-1130

Eisenberg, N., \& Spinrad T.L. (2004). Emotion-related regulation: sharpening the definition. Child Dev 75: 334-339.

Faraone SV, Biederman J \& Mick E (2006). The age-dependent decline of symptoms of ADHD: a meta-analysis of follow-up studies: Psychological Medicine, 36, 159-165. 
Frick PJ \& Morris AS (2004). Temperament and developmental pathways to conduct problems. Journal of Clinical Child and Adolescent Psychology, 33, 54-68.

Gershon AC, Gerring JP, Freund L, Joshi PT, Capozzoli J, Brady K, Denckla MB (1996) The children's affective lability scale: a psychometric evaluation of reliability. Psychiatry Research, 65, 189-198.

Goodman R (1997). The Strength and Difficulties Questionnaire: A research Note. Journal of Child Psychology and Psychiatry, 38, 581-586.

Grizenko N, Shayan Y, Polotskaia A, TerStepanian M \& Joober $R$ (2008). Relation of maternal stress during pregnancy to symptom severity and response to treatment in children with ADHD. Journal of Psychiatry and Neurosciences, 33, 10-16.

Gross, J.J., \& Thompson, R.A. (2007). Emotion regulation: Conceptual foundations. In: J.J. Gross (Ed.), Handbook of emotion regulation. New York: Guilford.

Hinshaw SP (2003) Impulsivity, emotion regulation and developmental psychopathology: specificity versus generality of linkages. Annals of the New York Academy of Sciences, 1008, 149-159.

Leung PWL, Luk SL, How TP, Taylor E, Mak $\mathrm{FL}$, \& Bacon-Shone J (1996). The diagnosis and prevalence of hyperactivity in Chinese schoolboys. British Journal of Psychiatry, 168, 486496.

Leibenluft E, Charney DS, Towbin KE, Bhangoo RK \& Pine DS (2003). Defining clinical phenotypes of juvenile mania. American Journal of Psychiatry, 160, 3, 430-436.

Leibenluft E, Cohen P, Gorrindo T, Brook JS \& Pine DS (2006). Chronic vs. episodic irritability in youth: a communitybased, longitudinal study of clinical and diagnostic associations. Journal of Child and Adolescent Psychopharmacology, 16, 456-466.

Maegden JW \& Carlson CL (2000). Social functioning and emotional regulation in the attention deficit hyperactivity disorder subtypes. Journal of Clinical Child Psychology, 29, 30-42.

Melnick, S.M., \& Hinshaw S.P. (2000). Emotion regulation and parenting in $\mathrm{AD} / \mathrm{HD}$ and comparison boys: linkages with social behaviors and peer preference. J Abnorm Child Psychol 28: 73-86.

Mick E, Spencer T, Wozniak J \& Biederman $J$ (2005). Heterogeneity of irritability in attention-deficit / hyperactivity disorder subjects with and without mood disorders. Biological Psychiatry, 58, 576-582.

Nigg JT (2003). Response inhibition and disruptive behaviours. Towards a multiprocess conception of etiological heterogeneity for ADHD combined type and conduct disorder early-onset type. Annals of the New York Academy of Sciences, 1008, 170-182.

Nigg JT, Goldsmith HH \& Sachek J (2004). Temperament and ADHD: The development of a multi-pathway model. Journal of Clinical Child Psychology, 33, 42-53.

Nigg, J.T., \& Casey, BJ (2005). An integrative theory of attention-deficit/ hyperactivity disorder based on the cognitive and affective neurosciences. Development and Psychopathology 17(3): 785-806.

Nigg JT (2006) Temperament and developmental psychopathology Journal of Child Psychology and Psychiatry, 47, 395-422 
Rucklidge JJ \& Tannock R (2001). Psychiatric, Psychosocial, and Cognitive Functioning of Female Adolescents with ADHD. Journal of the American Academy of Child and Adolescent Psychiatry, 40, 530-540.

Sattler JM (1992). Assessment of children: WISC-III and WPPSI-R supplement. San Diego, CA

Taylor E, Sandberg S, Thorley G \& Giles S (1991) The epidemiology of childhood hyperactivity. New York: Oxford University Press.

Skirrow, C., McLoughlin, G. Kuntsi, J., Asherson, P. (2009). "Behavioral, neurocognitive and treatment overlap between attention-deficit/hyperactivity disorder and mood instability." Expert Rev Neurother 9: 489-503.

Sonuga-Barke, E. J. (2003). The dual pathway model of AD/HD: an elaboration of neuro-developmental characteristics. Neurosci Biobehav Rev 27: 593-604.

Stringaris A \& Goodman R (2008) Mood lability and psychopathology in youth. Psychological Medicine, 38, 1-9.

Stringaris, A., \& Goodman, R. (2009). Three dimensions of oppositionality in youth. J Child Psychol Psychiatry 50: 216-23.

Tillman R \& Geller B (2005). A brief screening tool for a prepubertal and early adolescent bipolar disorder phenotype. American Journal of Psychiatry, 162, 1214-1221.

Walcott CM \& Landau S (2004). The relation between disinhibition and emotion regulation in boys with attention-deficit / hyperactivity disorder. Journal of Clinical Child \& Adolescent Psychology, 33, 772-782.

Westerlund J, Ek U, Holmberg K, Näswall K, Fernell E (2009) The Conners' 10item-scale: findings in a total population of Swedish 10-11-year-old children. Acta Paediatrica. E-pub ahead of print.

Whalen CK \& Henker B (1985). The social world of hyperactive (ADDH) children. Clinical Psychology Review, 5, 447-478.

Willcutt E, Sonuga-Barke E, Nigg J, Sergeant J (2008). Recent Developments in Neuropsychological Models of Childhood Psychiatric Disorders. In: Banaschewski T, Rohde LA (Eds): Biological Child Psychiatry. Recent Trends and Developments. Adv Biol Psychiatry. Basel, Karger, 2008, vol 24. 195-226.

Zelazo, P. D., \& Cunningham, W. (2007). Executive function: Mechanisms underlying emotion regulation. In J. Gross (Ed.), Handbook of emotion regulation.135-158. New York: Guilford 
